\title{
Modelling the dynamics of ambient dose rates induced by radiocaesium in the Fukushima terrestrial environment
}

\author{
Marc-André Gonze ${ }^{1, *}$, Christophe Mourlon ${ }^{1}$, Philippe Calmon ${ }^{2}$, Erwan $_{\text {Manach }}{ }^{3}$, Christophe Debayle $^{3}$ and \\ Jean $\mathrm{Baccou}^{4}$ \\ ${ }^{1}$ IRSN, Institute for radiological Protection and Nuclear Safety, Laboratoire de Modélisation pour \\ l'Expertise Environnementale (LM2E), 13115 St Paul-lez-Durance, France. \\ ${ }^{2} I R S N$, Institute for radiological Protection and Nuclear Safety, Laboratoire d'Études Radioécologiques en \\ milieux Continental et Marin (LERCM), 13115 St Paul-lez-Durance, France. \\ ${ }^{3}$ IRSN, Institute for radiological Protection and Nuclear Safety, Laboratoire de Surveillance \\ Atmosphérique et d'Alerte (LS2A), 78116 Le Vésinet, France. \\ ${ }^{4}$ IRSN, Institute for radiological Protection and Nuclear Safety, Laboratoire Incertitude et Modélisation \\ des Accidents de Refroidissement (LIMAR), 13115 St Paul-lez-Durance, France.
}

\begin{abstract}
Since the Fukushima accident, Japanese scientists have been intensively monitoring ambient radiations in the highly contaminated territories situated within $80 \mathrm{~km}$ of the nuclear site. The surveys that were conducted through mainly carborne, airborne and in situ gamma-ray measurement devices, enabled to efficiently characterize the spatial distribution and temporal evolution of air dose rates induced by Caesium134 and Caesium-137 in the terrestrial systems. These measurements revealed that radiation levels decreased at rates greater than expected from physical decay in 2011-2012 (up to a factor of 2), and dependent on the type of environment (i.e. urban, agricultural or forest). Unlike carborne measurements that may have been strongly influenced by the depuration of road surfaces, no obvious reason can be invoked for airborne measurements, especially above forests that are known to efficiently retain and recycle radiocaesium.
\end{abstract}

\begin{abstract}
The purpose of our research project is to develop a comprehensive understanding of the data acquired by Japanese, and identify the environmental mechanisms or factors that may explain such decays. The methodology relies on the use of a process-based and spatially-distributed dynamic model that predicts radiocaesium transfer and associated air dose rates inside/above a terrestrial environment (e.g., forests, croplands, meadows, bare soils and urban areas).
\end{abstract}

\begin{abstract}
Despite the lack of site-specific data, our numerical study predicts decrease rates that are globally consistent with both aerial and in situ observations. The simulation at a flying altitude of $200 \mathrm{~m}$ indicated that ambient radiation levels decreased over the first 12 months by about $45 \%$ over dense urban areas, $15 \%$ above evergreen coniferous forests and between 2 and $12 \%$ above agricultural lands, owing to environmental processes that are identified and discussed. In particular, we demonstrate that the decrease over evergreen coniferous regions might be due the combined effects of canopy depuration (through biological and physical mechanisms) and the shielding of gamma rays emitted from the forest floor by vegetation. Our study finally suggests that airborne surveys might have not reflected dose rates at ground level in forest systems, which were predicted to slightly increase by 5 to $10 \%$ during the same period of time.
\end{abstract}

\footnotetext{
*Corresponding author: marc-andre.gonze@irsn.fr
} 


\section{Modelling the dynamics of} Ambient Dose Rates in Fukushima terrestrial environments

Gonze M.A., Mourlon C., Calmon P., Baccou J., Manach E. \& Debayle C.

IRSN

CE Cadarache (France) 


\section{Field surveys of Ambient Dose Rates (ADRs)}

Coordinated by the Japanese Nuclear Regulatory Authority / Atomic Energy

Airborne (dec. 2012)

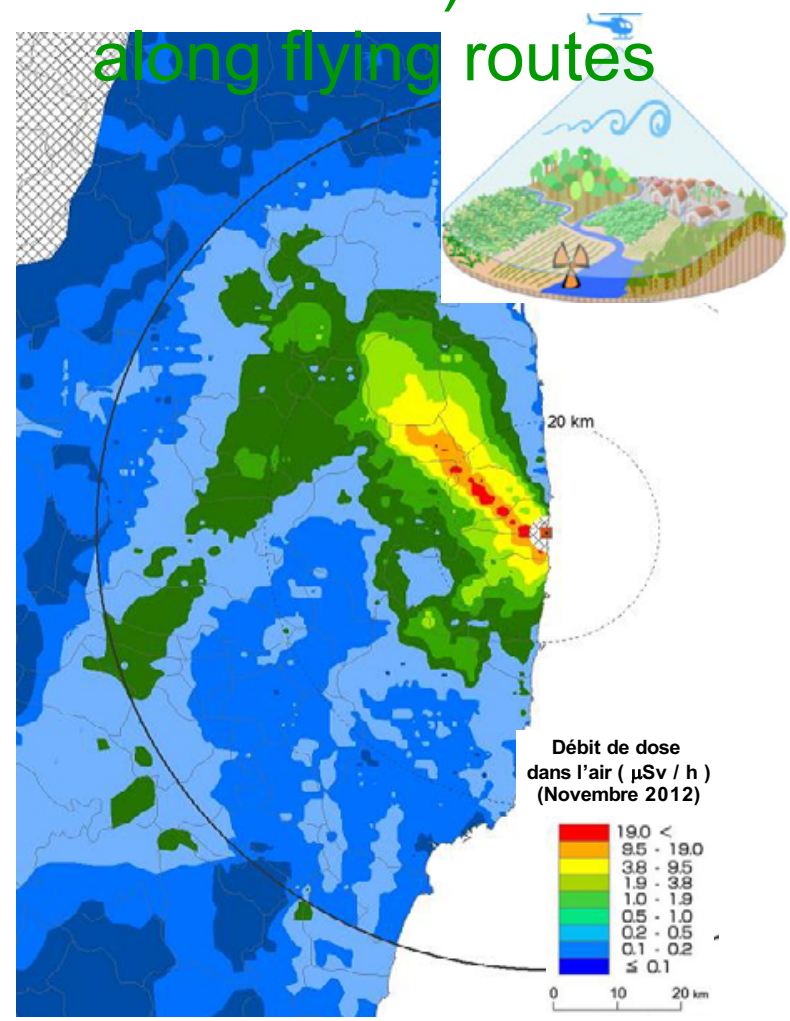

Agency
Carborne (dec. 2012)

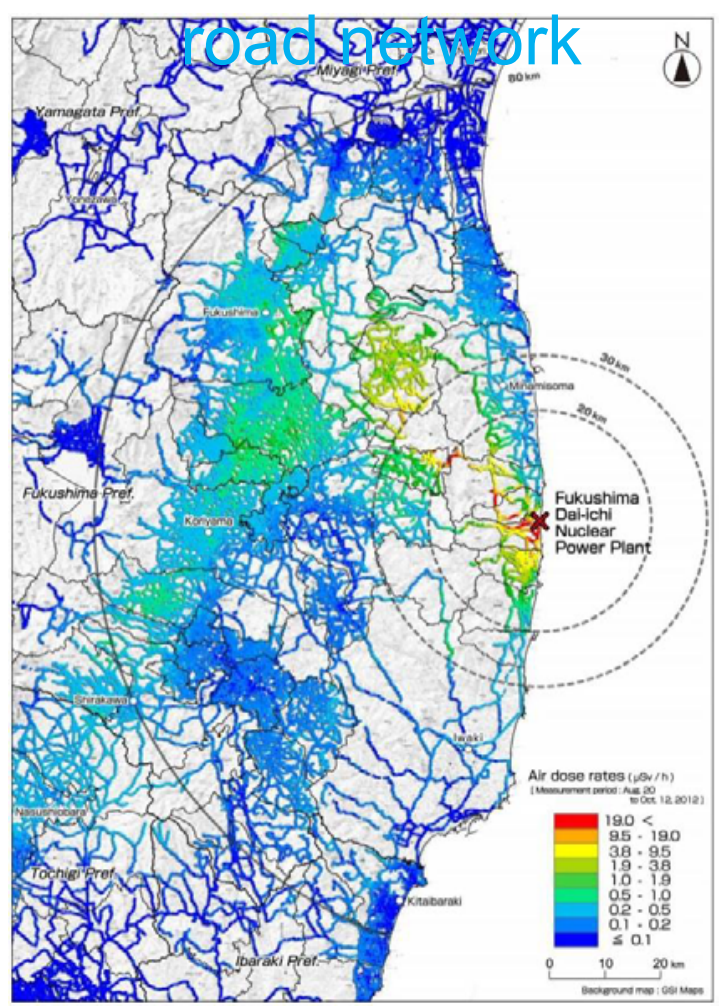

In situ (dec. 2012) of undisturbed bare soils

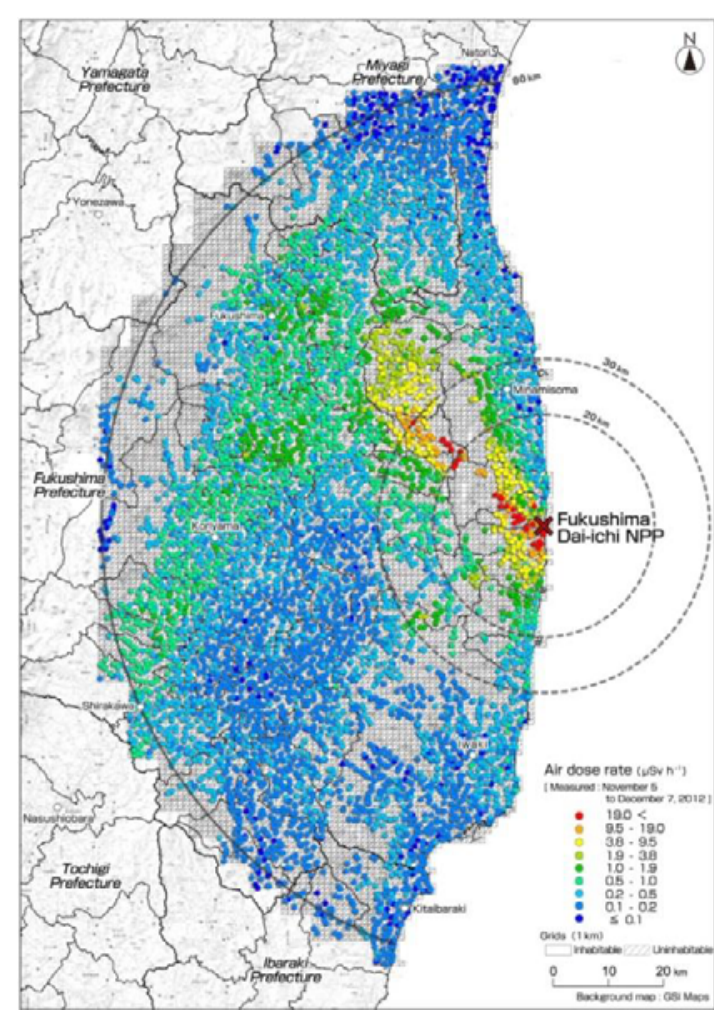

Sanada et al., 2012; Sanada et al. 2014a,b; Tsuda and Tsusumi, 2012; Tsuda et al. 2014; Tanigaki et al., 2013; Kinase et al., 2014; Andoh et al., 2014; Mikami et al., 2014a; Mikami et al., 2014b; Onda et al., 2014; Saito et al., 2014a; Saito et al., 2014b; Matsuda et al., 2014 


\section{Aerial versus in situ (Oct. 2011 )}

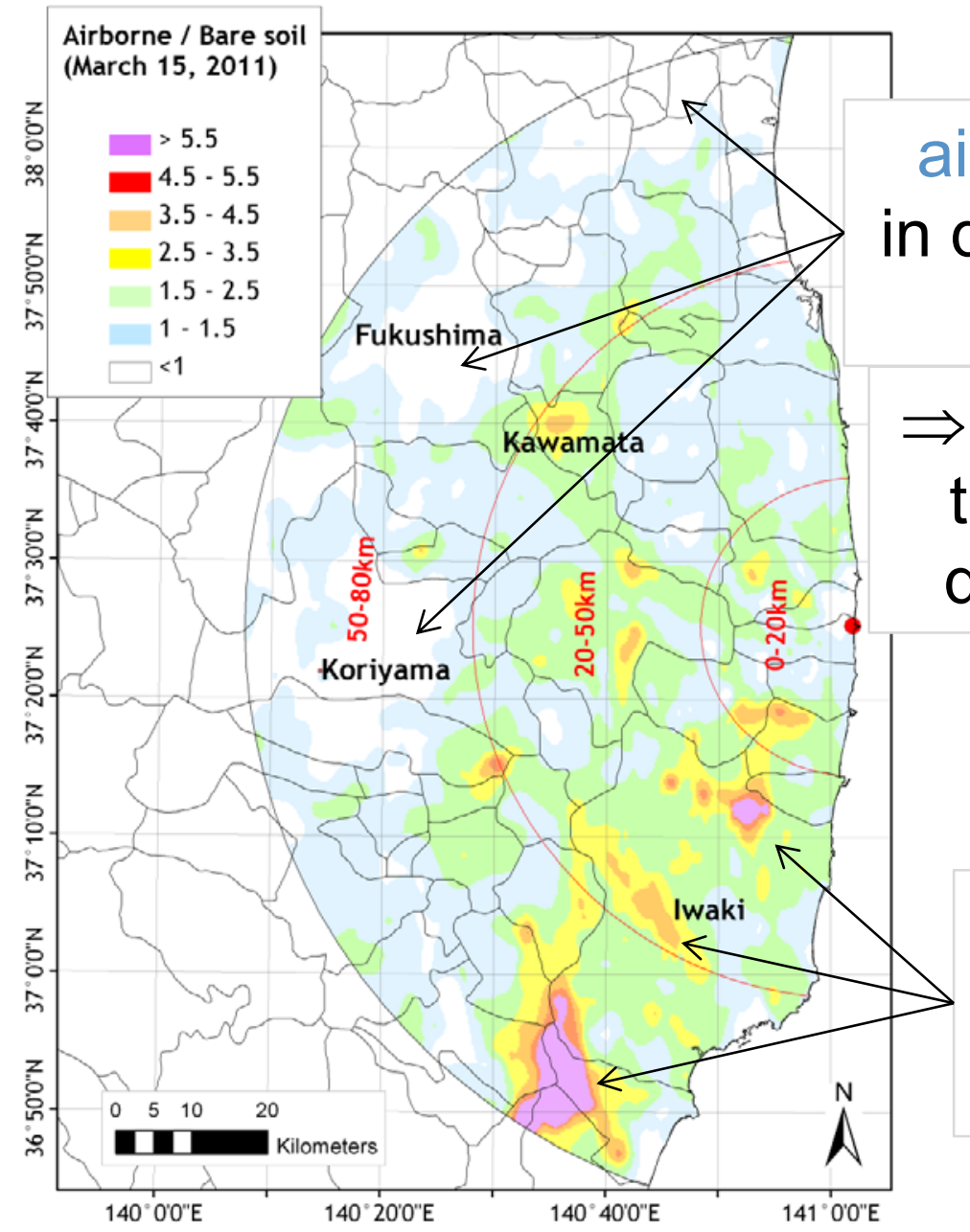

Gonze et al., ES\&T 2014 airborne < in situ in densily inhabited areas

$\Rightarrow$ natural wash-off, traffic erosion \& decontamination

airborne $>3 x$ in situ in evergreen coniferous forests

$\Rightarrow$ dry atmospheric deposition

Crop

Paddy
Bare land Urban

Water
Landuse map

Land use map (ALOS, $30 \times 30 \mathrm{~m}$ )

Deciduous forest

Evergreen forest be

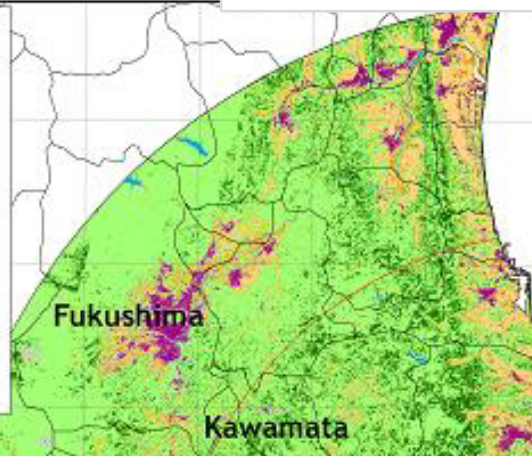

Kawamata
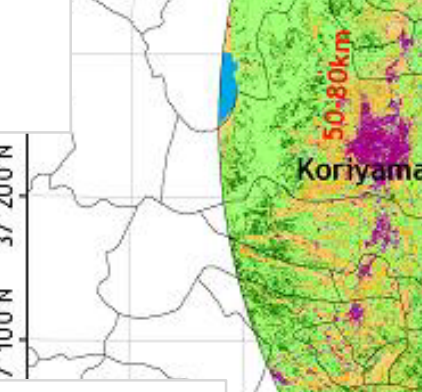

Koriyana

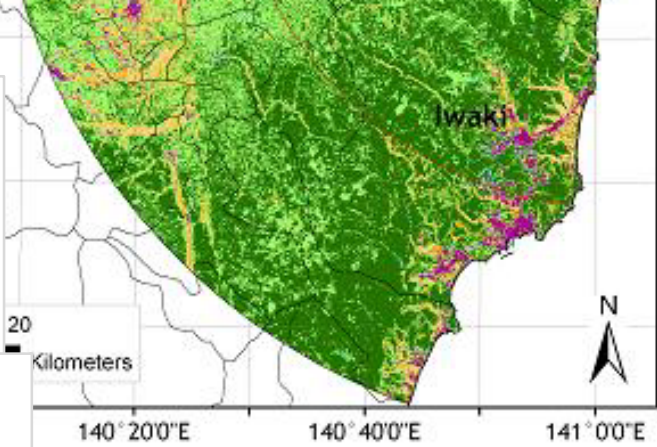

$140^{\circ} 200^{\prime \prime} \mathrm{E}$ $141^{\circ} \mathrm{OO} \mathrm{E}$

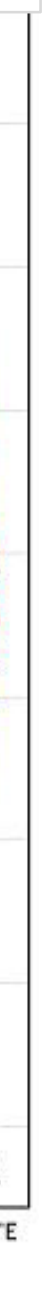




\section{Time decrease of ADRs (1m height)}

... averaged within $80 \mathrm{~km}$ \& normalized by its value in June 2011

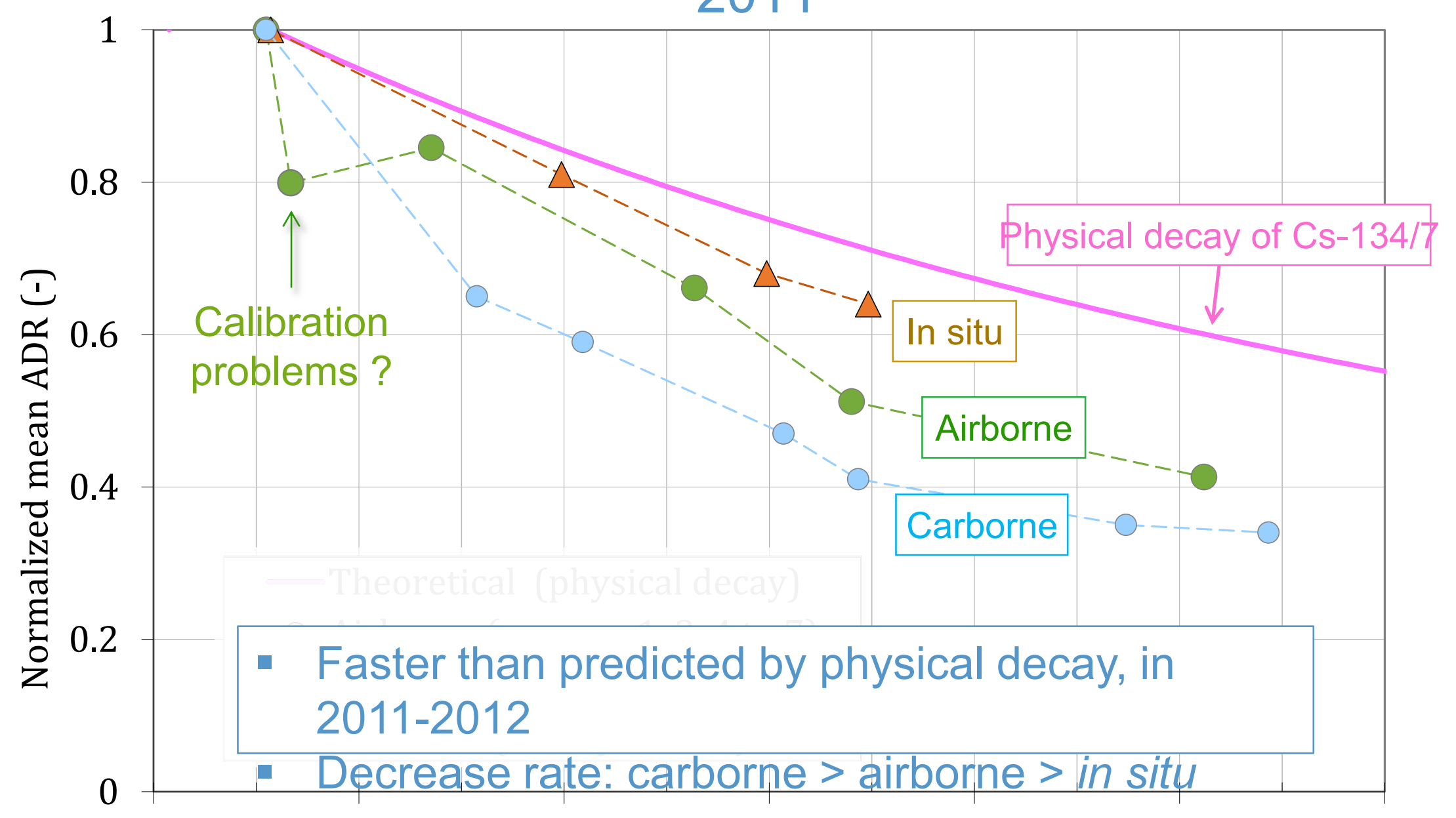

$\begin{array}{lllllll}03 / 2011 & 09 / 2011 & 03 / 2012 & 09 / 2012 & 03 / 2013 & 09 / 2013 & 03 / 2014\end{array}$ 


\section{Time decrease of ADRs (1m height)}

... averaged within $80 \mathrm{~km}$ \& normalized by its value in June 2011

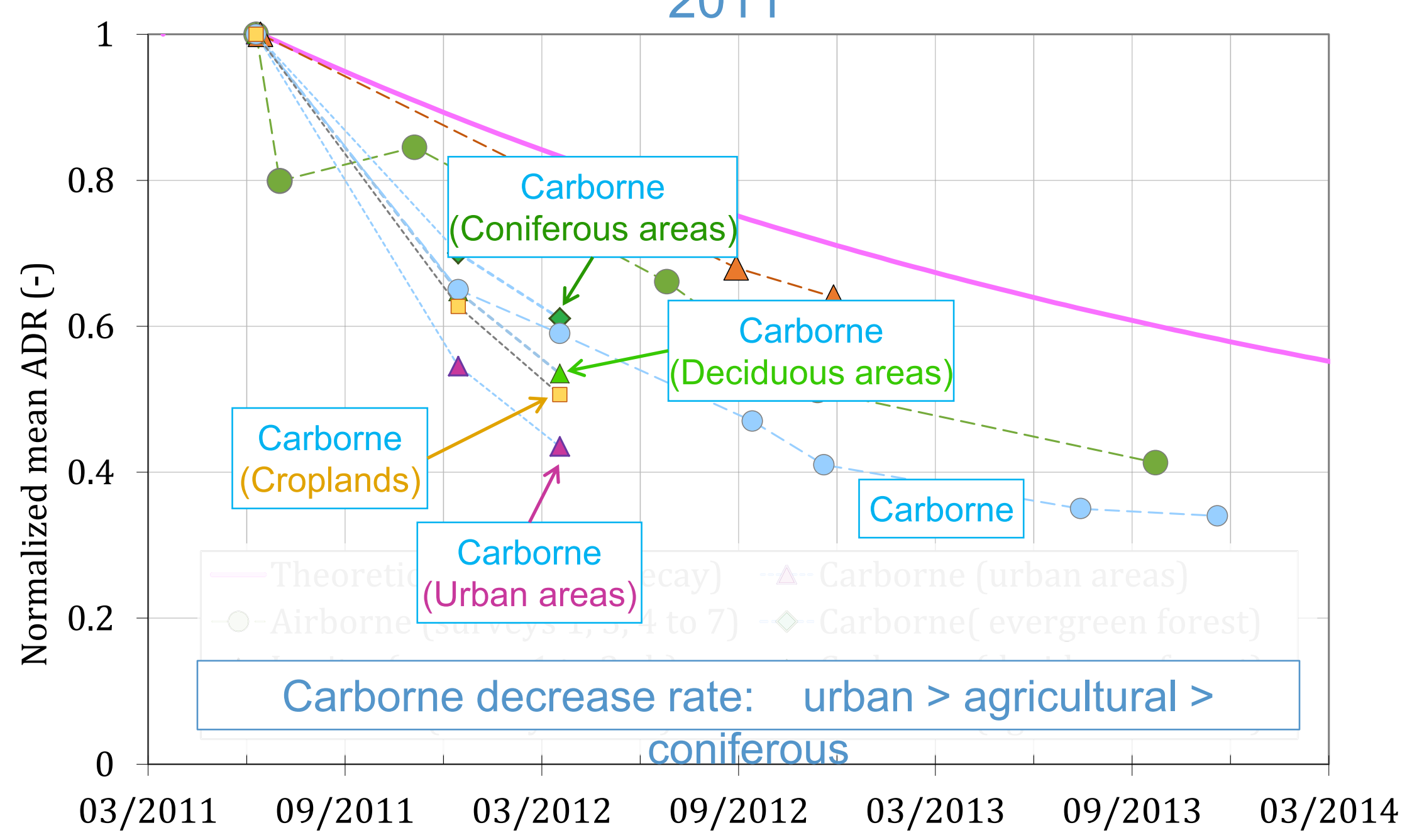




\section{Ongoing research projects}

Open questions

- Which environmental processes could explain such a variability in ADRs ?

- To what extent can forest vegetation modify ADRs inside/above forests ?

- Can we gain further understanding from process-based \& dynamic models?

AMORAD project (2013-2019) Improvement of models for predicting radionuclide transfer in biosphere, with one focus put on

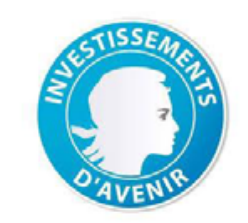

forest systems

French National Research Agency

\section{EDOFU project (2014-2016)} Improvement of models for predicting $\gamma$ ADRs in a multimedia and patchy environment

eDF Electricité de France

http://www.irsn.fr/EN/Research/Research-organisation/Researchprogrammes/Pages/Research-programmes-2966.aspx 


\section{Modeling Cs transfer...}

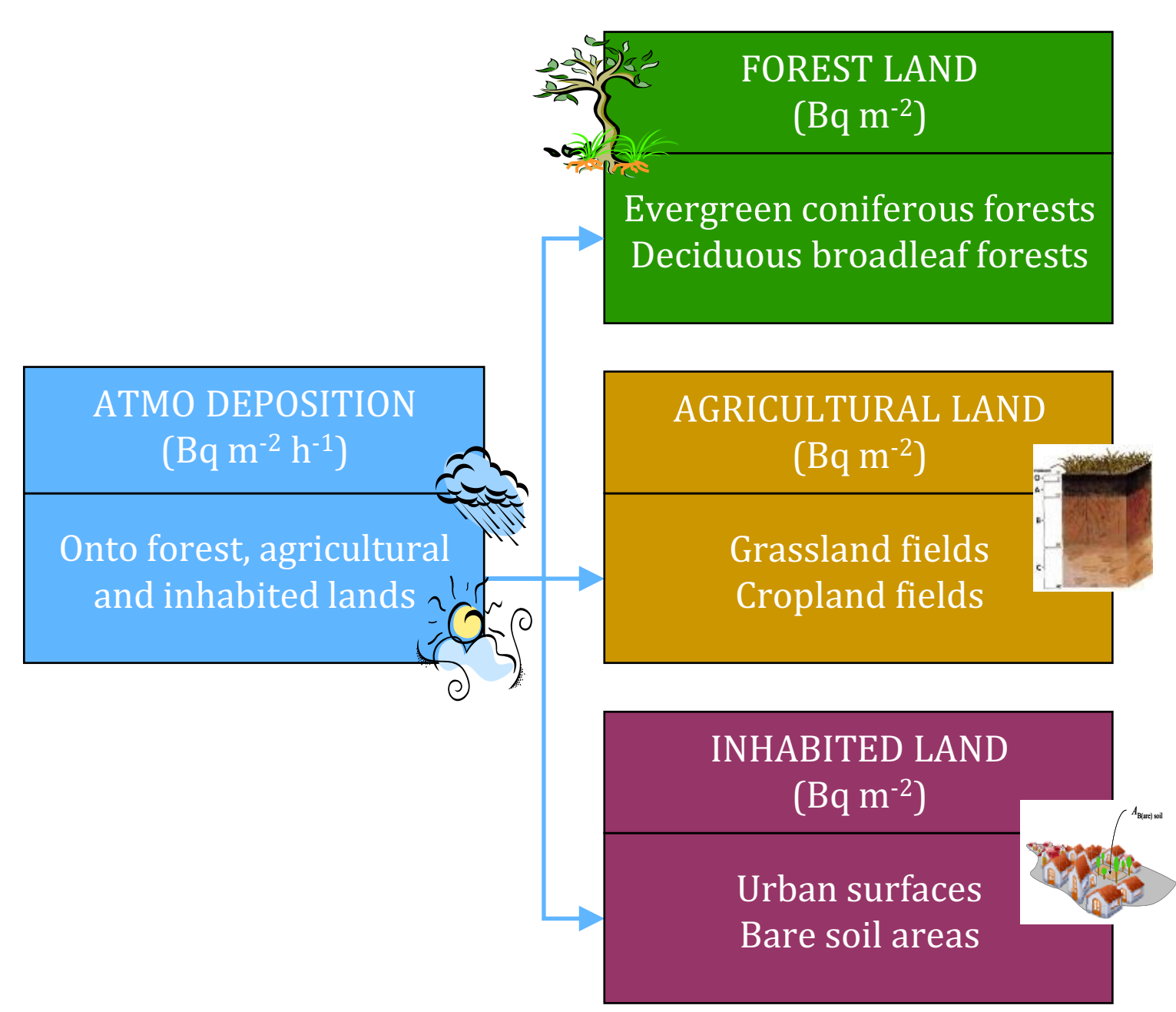

Key processes or factors that are likely to influence ADRs:

- Dry/wet deposition

- Interception by vegetation

- Depuration of vegetation

\section{IRSN's modelling platform (SYMBIOSE)}

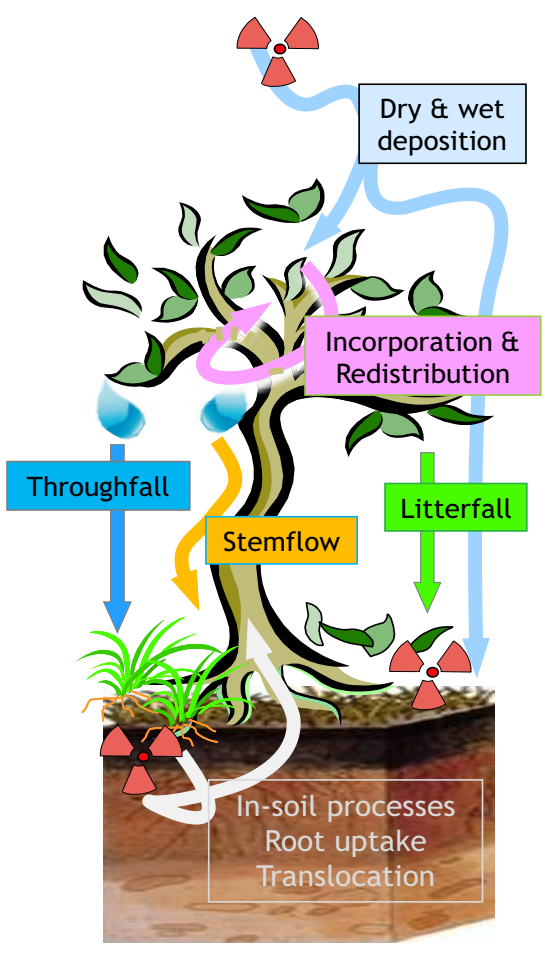




\section{Modeling Cs transfer ...}

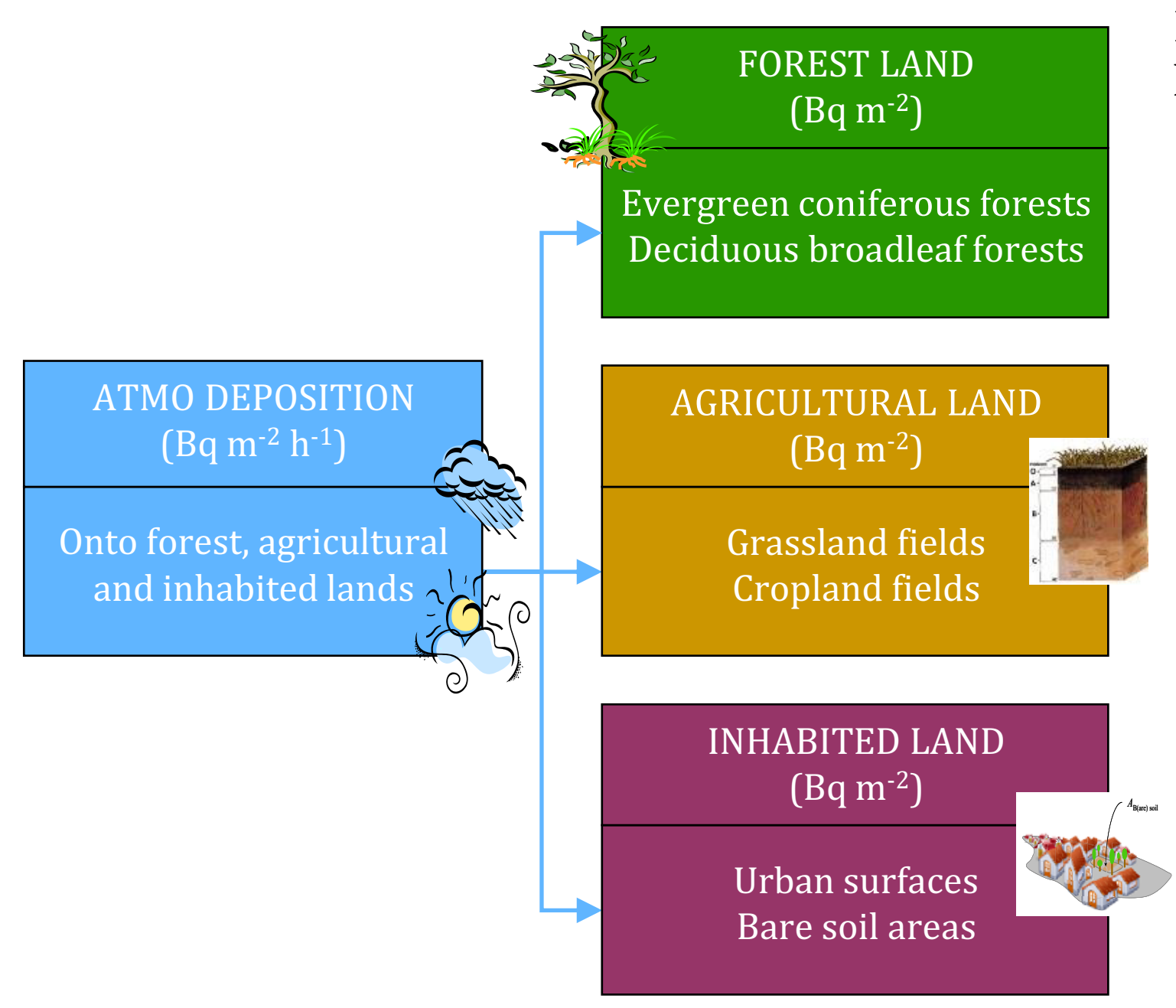

IRSN's modelling platform (SYMBIOSE)
Key processes or factors that are likely to influence ADRs:

- Dry/wet deposition

- Interception by vegetation

- Depuration of vegetation

- Ploughing of cultivated soils

- Harvesting of crops

- Flooding of paddy fields

- Vertical migration within soils

- Depuration \& decontamination of urban surfaces

- Influence of road \& roadside on carborne DRs (not accounted for)

- Influence of snow cover (not accounted for) 


\section{$\ldots$ and ADRs}

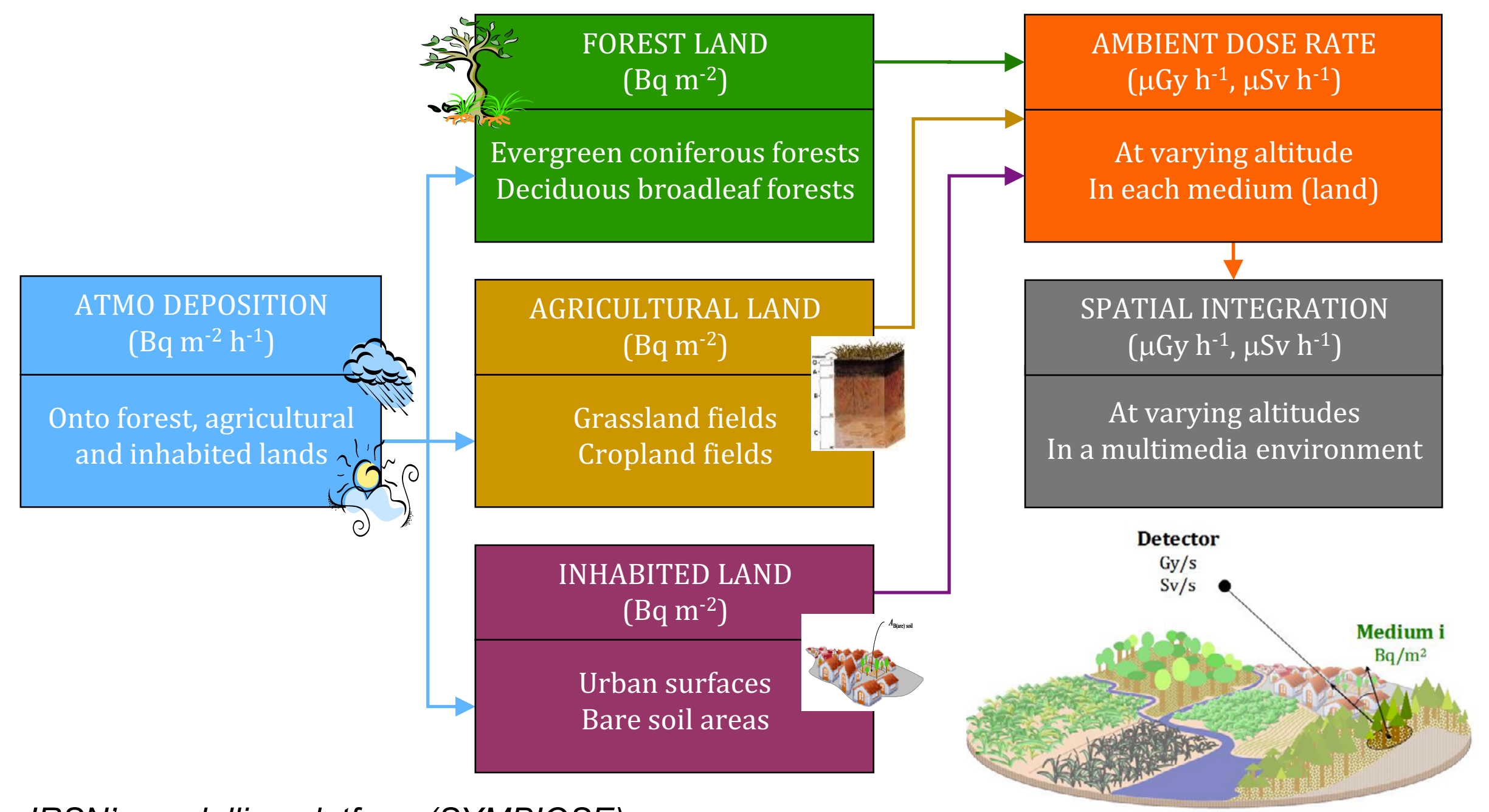

\section{IRSN's modelling platform (SYMBIOSE)}




\section{ADR coefficients for a soil-vegetation}

Use of:

\section{medium}

- ADR coefficients expressed in $(\mathrm{Gy} / \mathrm{h}) /\left(\mathrm{Bq} / \mathrm{m}^{2}\right)$

- Pre-calculated with MCNP code

- Depending on detector altitude, depth of source and medium characteristics (e.g., geometry, density \& elemental composition)

\section{Equivalent Medium assumption}

- Soil, vegetation \& atmosphere layers with homogeneous properties

- Plane or volumetric radioactive source of homogeneous intensity

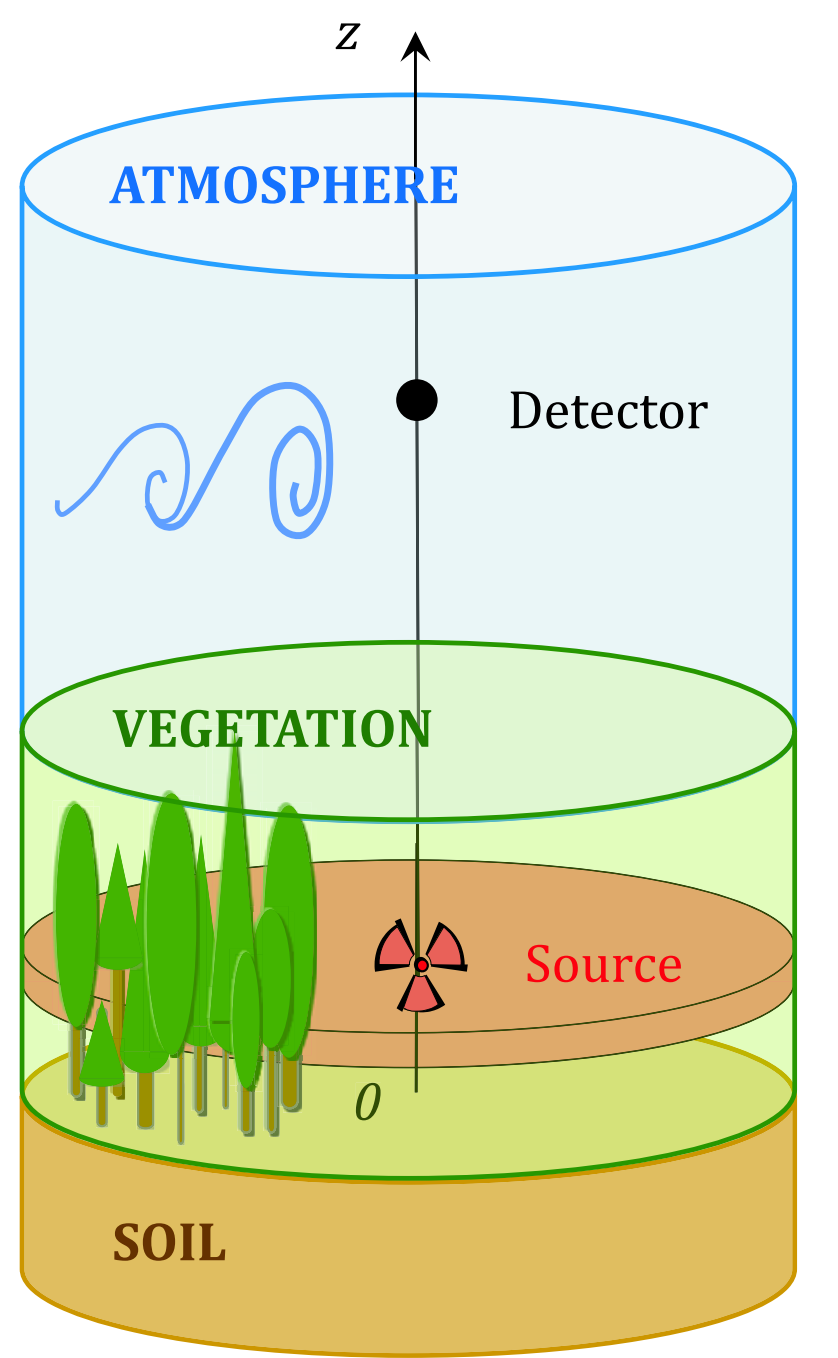




\section{Regional simulations}

- Spatio-temporal domain

- 80 km from FDNPP

- Computational regular grid

- March 2011 to March 2014 (3 years)

- Environmental parameters

- Mostly generic

- A few site-specific

- Land use map

- Cs contamination maps (airborne \& in sitú)

- Seasonal climatic data

- Agricultural practices

- Depuration/decontamination rates for urban surfaces

- Depuration of forest vegetation

○ $\ldots$

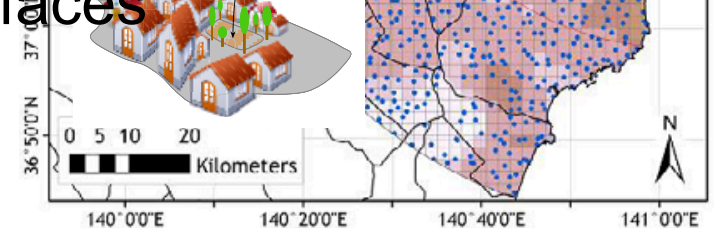




\section{Tree depuration flux at 21 evergreen coniferous sites}

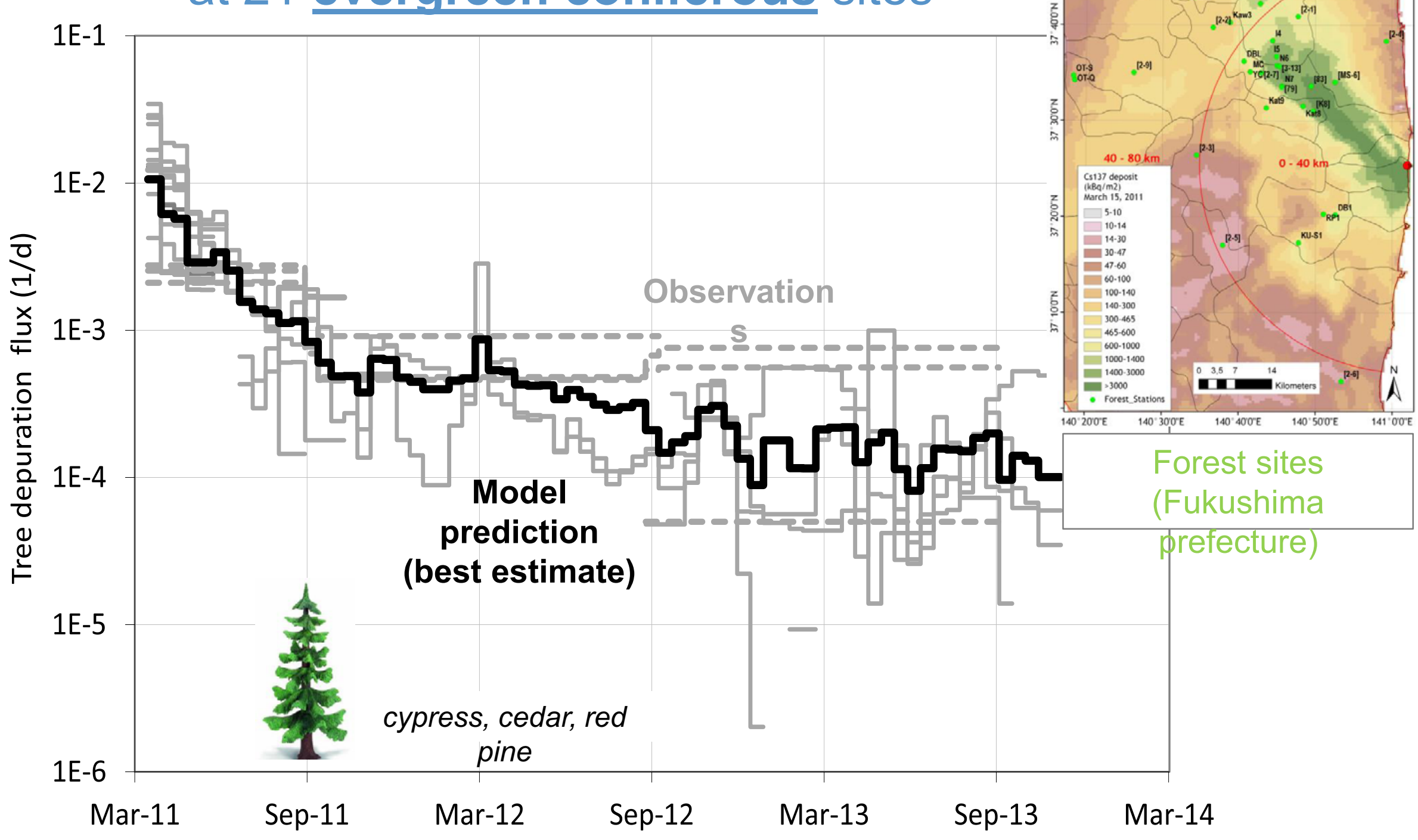




\section{... and inventory in soil \\ at 21 evergreen coniferous sites}

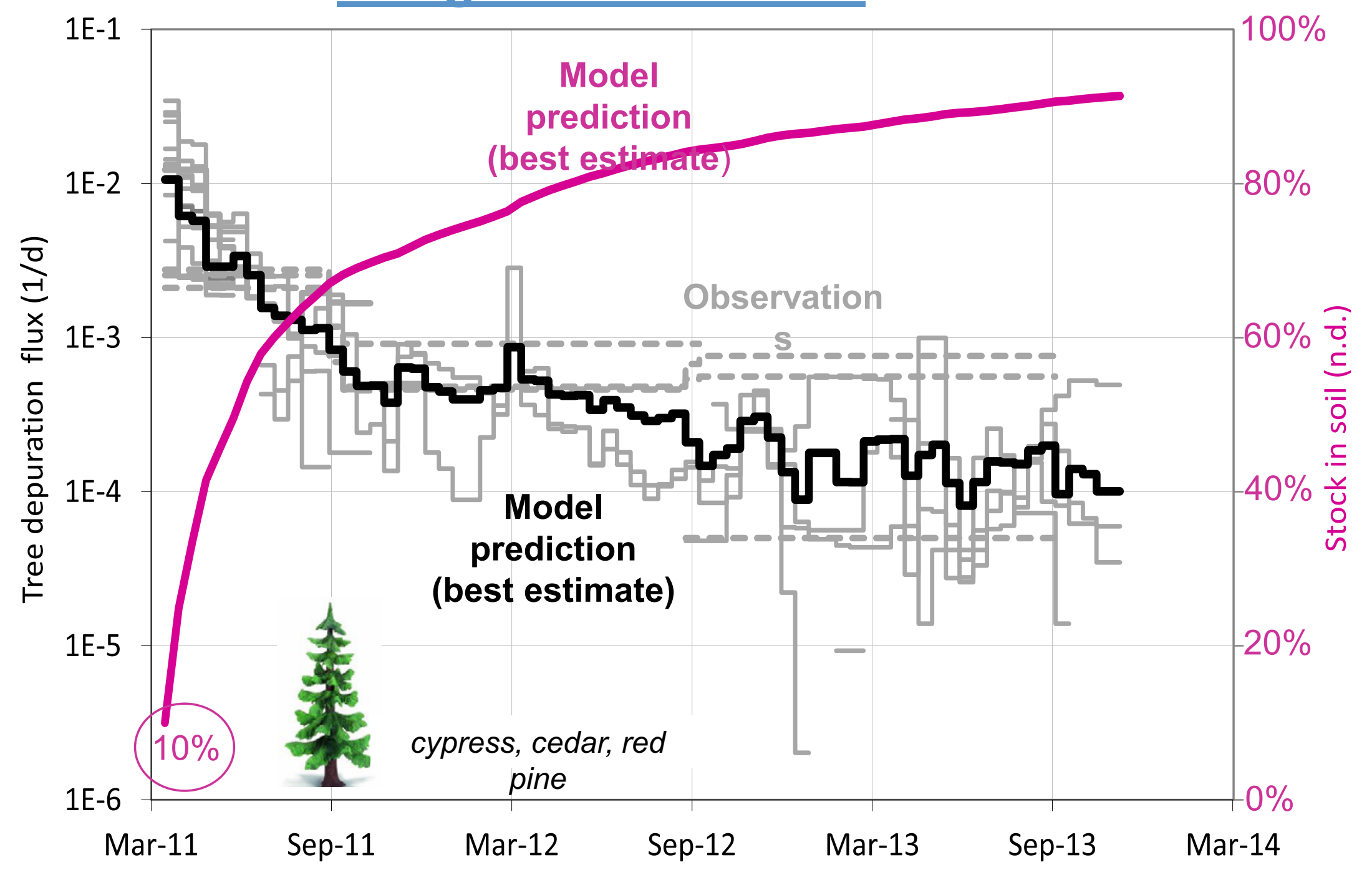




\section{Deciduous broadleaf forests (4 sites)}

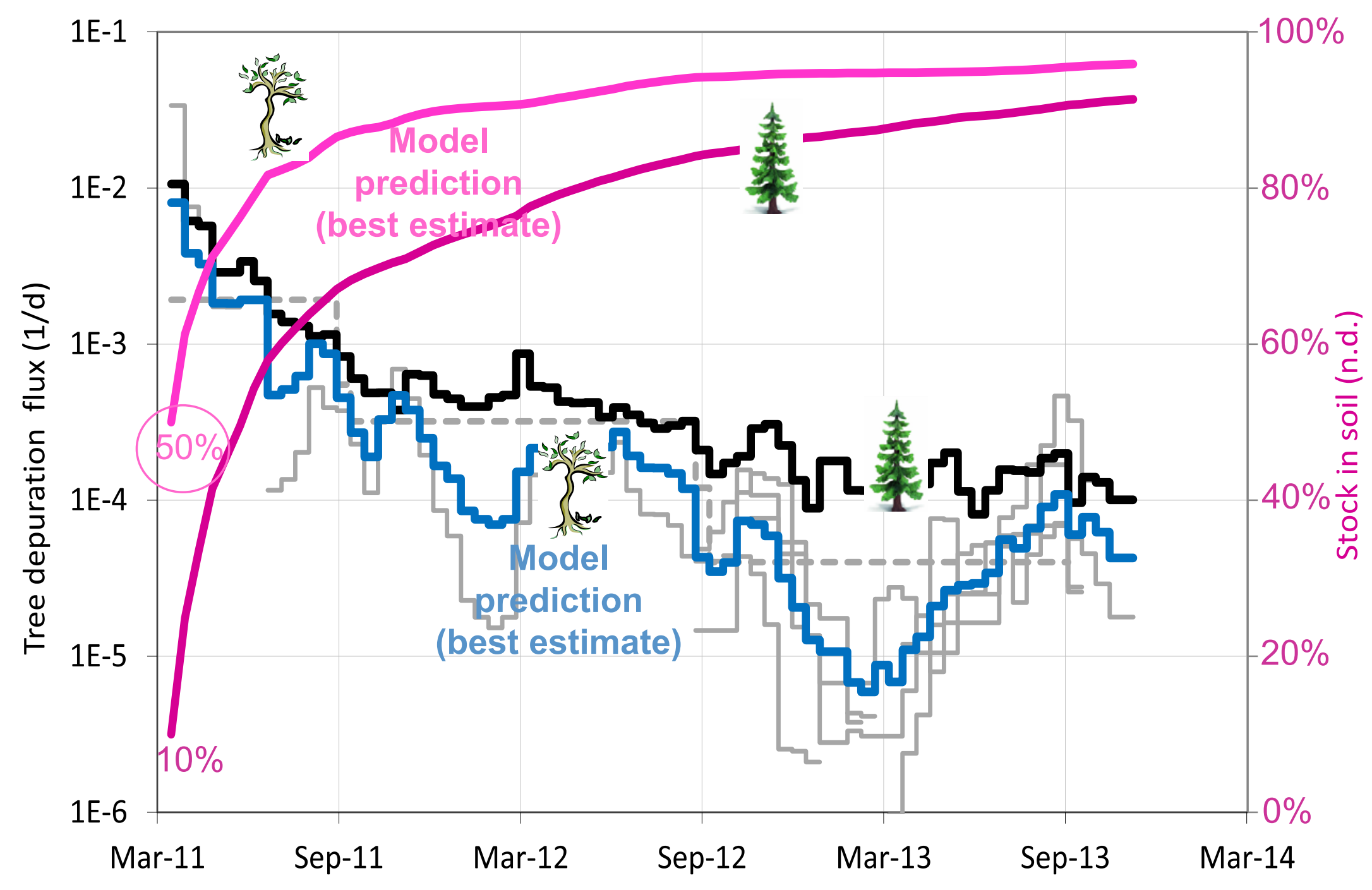

ICRS-13 \& RPSD-2016 conference, Paris, Oct. 2016 


\section{ADR coefficient in a coniferous forest ... for a plane source of ${ }^{134} \mathrm{Cs}$ of increasing height}
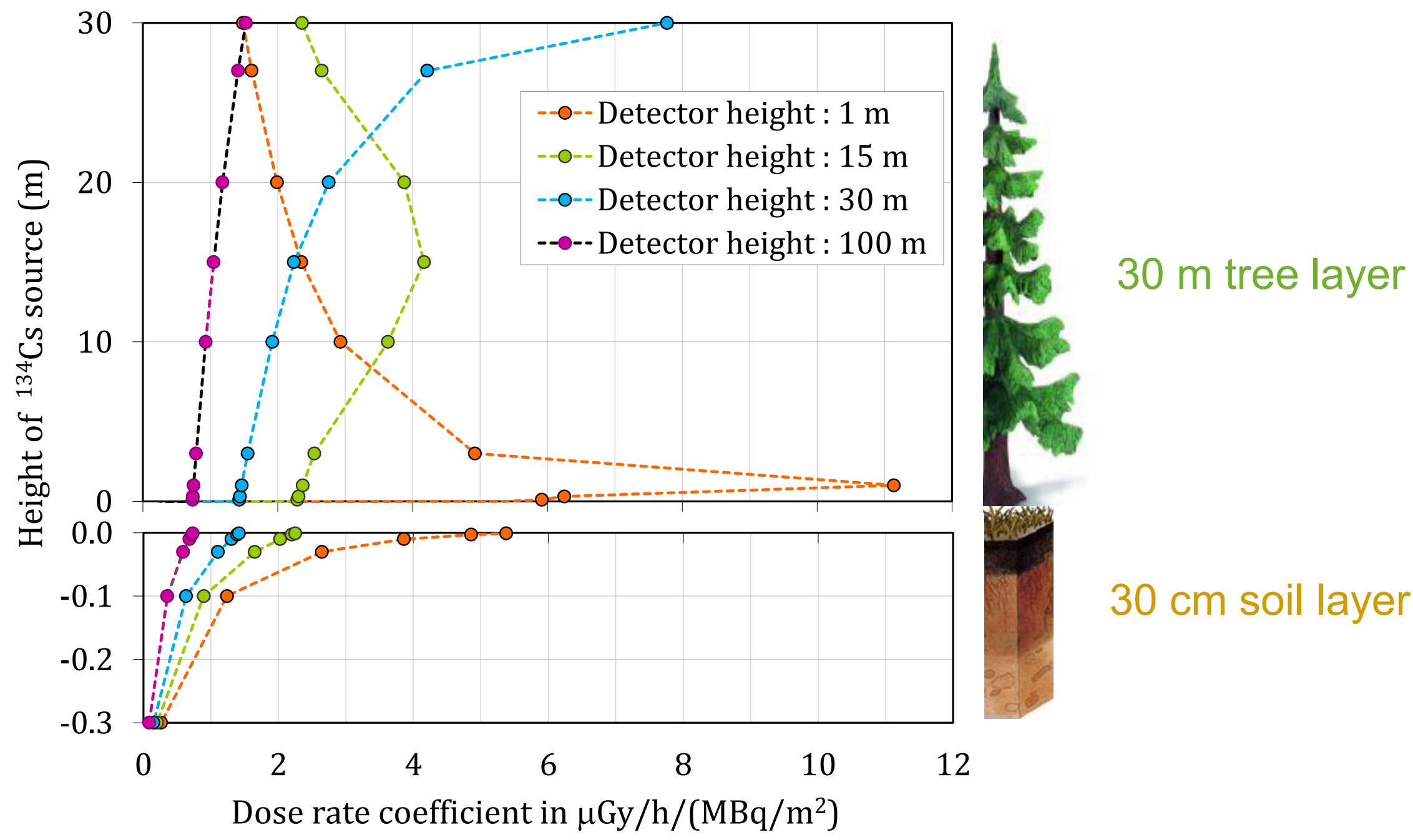


\section{ADR coefficients in a coniferous forest} for a volumic source of ${ }^{134} \mathrm{Cs}$ in the top $1 \mathrm{~cm}$ soil layer or $30 \mathrm{~m}$

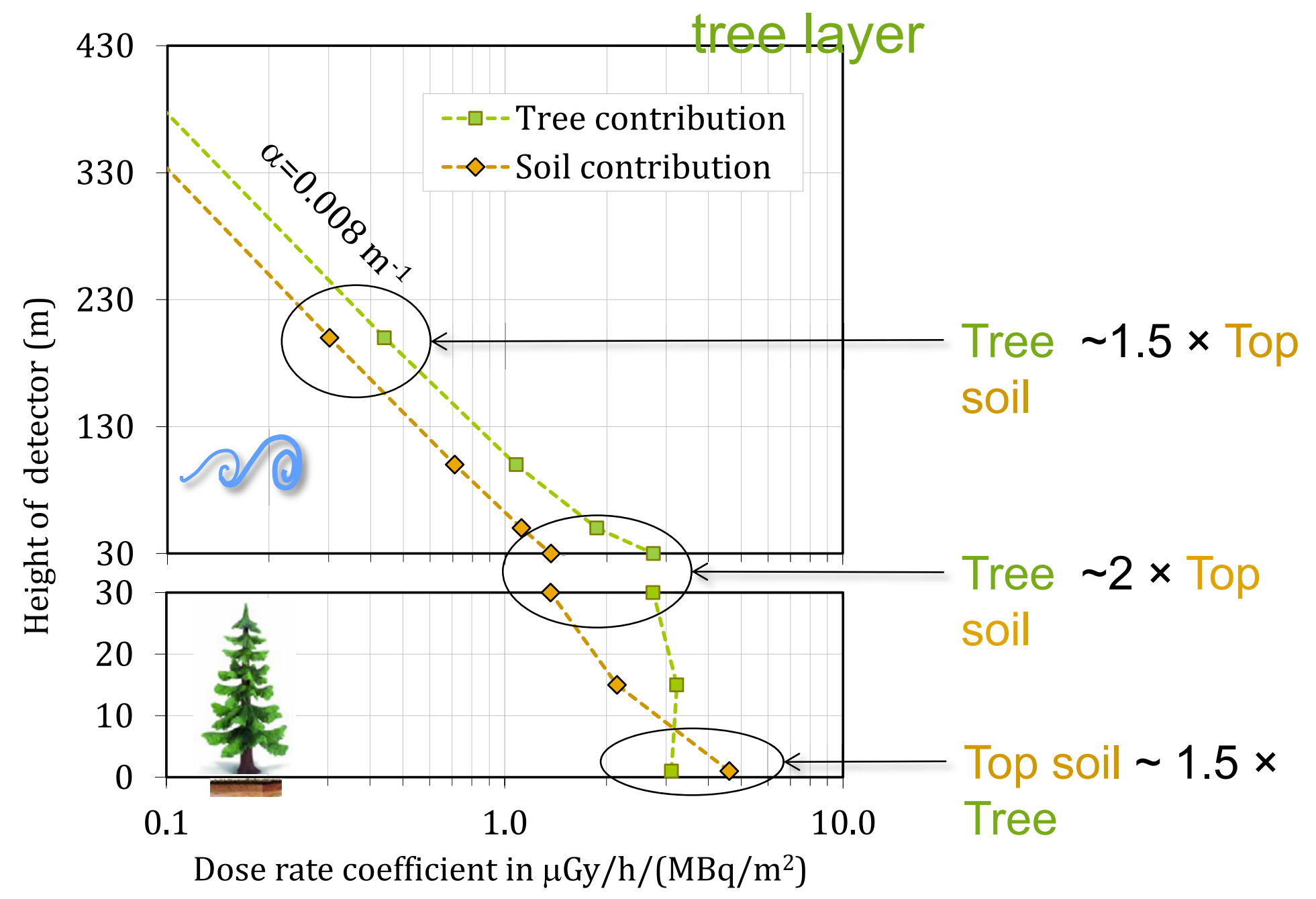




\section{Predicted ADRs at ground level $\left({ }^{134+7} \mathrm{Cs}\right) \ldots$}

Mean value within the $80 \mathrm{~km}$ region and normalized by its value in June 2011

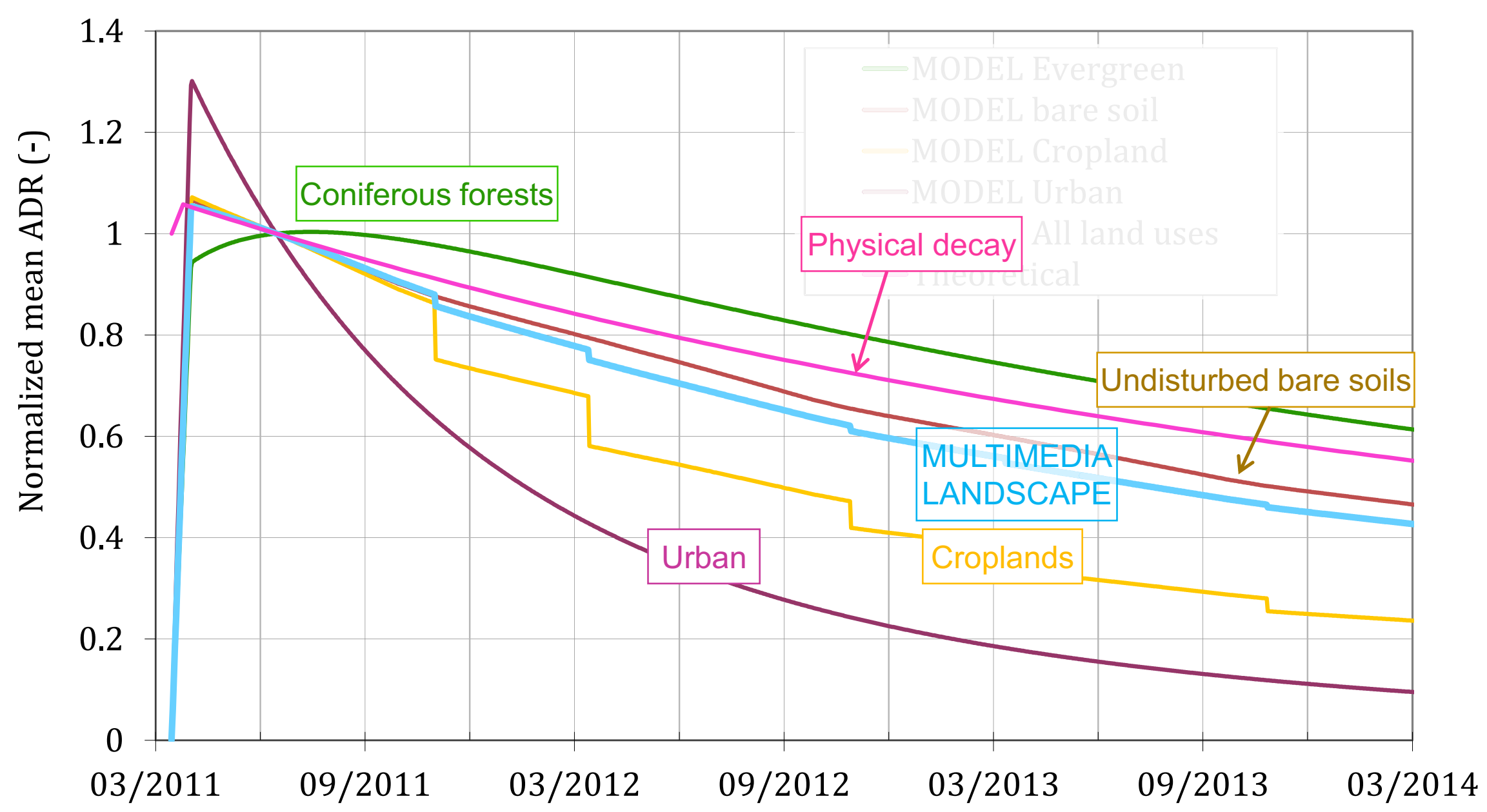




\section{...versus in situ \& carborne data}

Mean value within the $80 \mathrm{~km}$ region and normalized by its value in June 2011

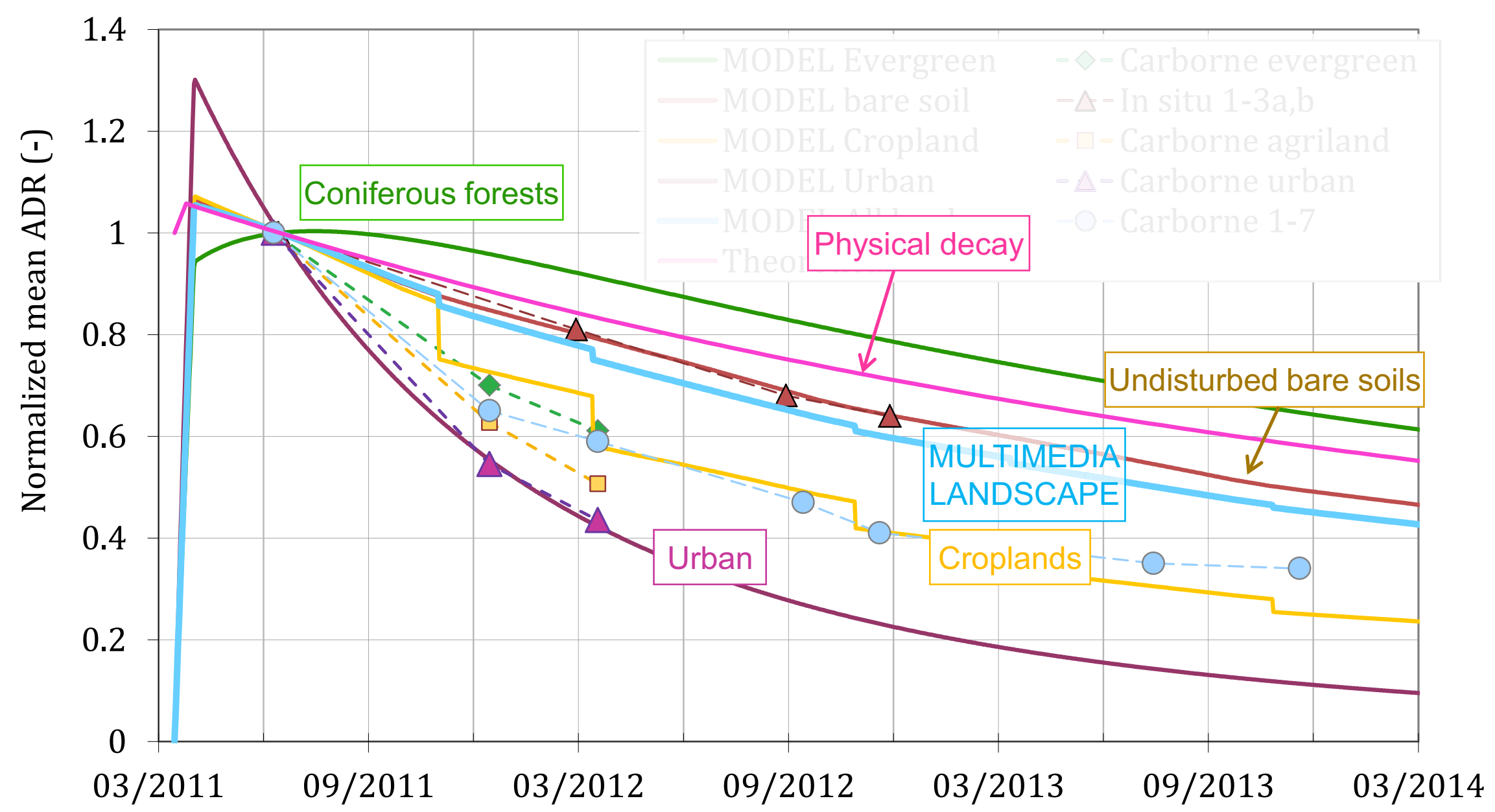




\section{Predicted ADRs at $200 \mathrm{~m} v \epsilon$}

Mean value within the $80 \mathrm{~km}$ region Gna

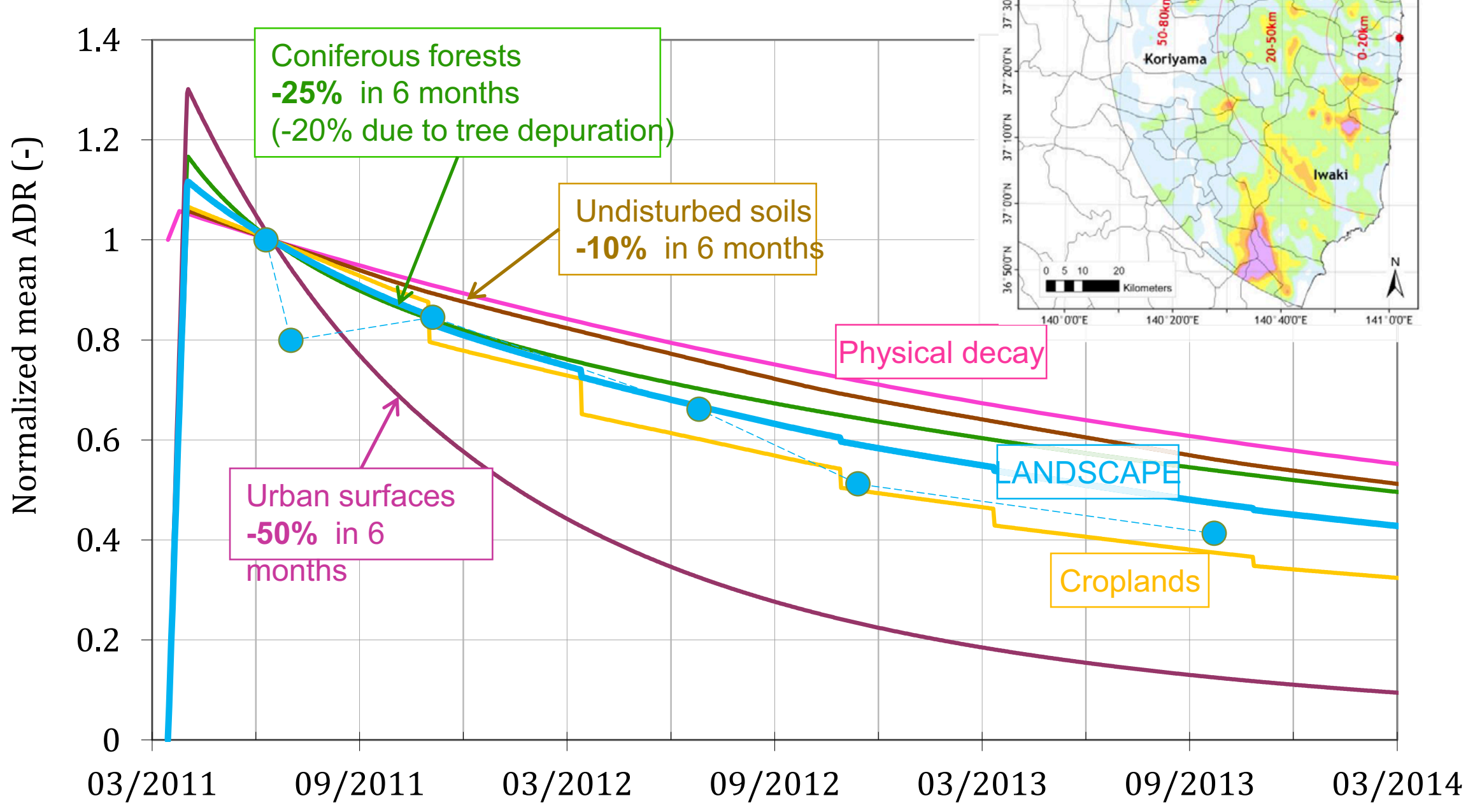




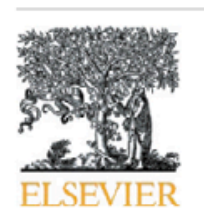

Contents lists available at ScienceDirect

Science of the Total Envirol $\mathrm{m}$

journal homepage: www.elsevier.com/locate/scitotenv

Modeling the early-phase redistribution of radiocesium fallouts in evergreen coniferous forest after Chernobyl and Fukushima accide

P. Calmon, M.-A. Gonze *, Ch. Mourlon

Institute of Radiation Protection and Nuclear Safety. CE Cadarache-Bat 153, BP3-13115 St-Paul-lez-Durance Cedex, France

HIGHLIGHTS

- Transfer of radiocesium atmospheric fallout in evergreen forests was modeled.

- The model was tested using observations from Chernobyl and Fukushima accidents.

- Model predictions of canopy interception and depuration agree with measurements.

- Unexpectedly high contribution of litterfall for the Japanese forest is discussed.

etails hink

- Unexpectedly high contribution of litterfall for the Japanese forest is discussed.

Journal of Environmental Radioactivity xxx (2015) 1-13

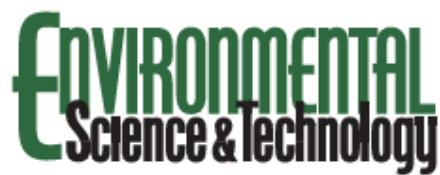

Assessment of Dry and Wet Atmospheric Deposits of Radioactive Aerosols: Application to Fukushima Radiocaesium Fallout

Marc-André Gonze, ${ }^{, \dagger}{ }^{\dagger}$ Philippe Renaud, ${ }^{\dagger}$ Irène Korsakissok, ${ }^{\frac{\vec{p}}{}}$ Hiroaki Kato, ${ }^{\S}$ Thomas G. Hinton, ${ }^{\dagger}$ Christophe Mourlon, ${ }^{\dagger}$ and Marie Simon-Cornu

Institute for Radiological Protection and Nuclear Safety (IRSN), Environmental Research Division, BP 3-13115 St-Paul-lez-Durance Cedex, France

"Institute for Radiological Protection and Nuclear Safety (IRSN), Nuclear \& Radiological Emergency Division, BP 17-92262

Contents lists available at ScienceDirect

\begin{tabular}{lcl}
\hline & Contents lists available at ScienceDirect \\
\hline ELSEVIER & Journal of Environmental Radioactivity \\
\hline
\end{tabular}

Modelling the dynamics of ambient dose rates induced by radiocaesium in the Fukushima terrestrial environment

Marc-André Gonze ${ }^{a}$, , Christophe Mourlon ${ }^{a}$, Philippe Calmon ${ }^{b}$, Erwan Manach ${ }^{c}$, Christophe Debayle ${ }^{c}$, Jean Baccou ${ }^{d}$

a Institut de Radioprotection et de Sûreté Nucléaire (IRSN), Laboratoire de Modélisation pour l'Expertise Environnementale (LMZE), Cadarache, 159, 13115 St Paul-lez-Durance, France

${ }^{\mathrm{b}}$ Institut de Radioprotection et de Sûreté Nucléaire (IRSN), Laboratoire d'Etudes Radioécologiques en milieux Continental et Marin (IERCM), C Bâtiment 151, 13115 St Paul-lez-Durance, France

'Institut de Radioprotection et de Sûreté Nucléaire (IRSN), Laboratoire de Surveillance Atmosphérique et d’Alerte (ISZA), Le Vésinet, Bâtiment C8, I8ITO Vesinet, France

anstitut de Radioprotection et de Sûreté Nucléaire (IRSN), Laboratoire Incertitude et Modélisation des Accidents de Refroidissement (LMAR), Cadarache Bâtiment 700, St Paul-lez-Durance 13115, France

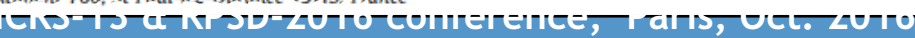
namics, University of Tsukuba,1-1-1 Tennodai, Tsukuba, Ibaraki Japan

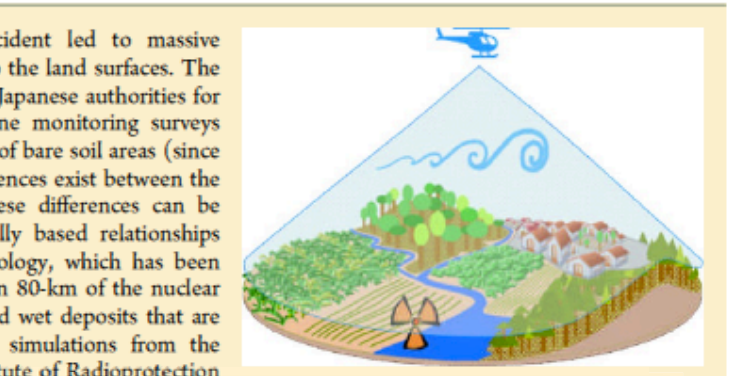
simulations from the

Compilation \& analysis of monitoring observations in Japanese forests to be

puplished shortly 


\section{Summary}

- Japanese data highly valuable for improving our understanding of post-accidental consequences in terrestrial systems

- Despite the lack of site-specific data \& uncertainties on deposition characteristics, predicted ADRs globally consistent with field observations (thanks to some models improvement \& calibration)

- This study suggests that:

- Disagreement with carborne observations mostly attributed to road \& roadside effects (not accounted for in our modelling study)

- Airborne observations above vegetation may not be representative of ground ADRs, due to tree depuration \& shielding of gamma rays

- Influence of forest vegetation should be accounted for when converting counting rates (for especially low flying altitudes) $\Rightarrow>$ this requires assumptions on radionuclide distribution! 


\section{Predicted wet deposition ratio}

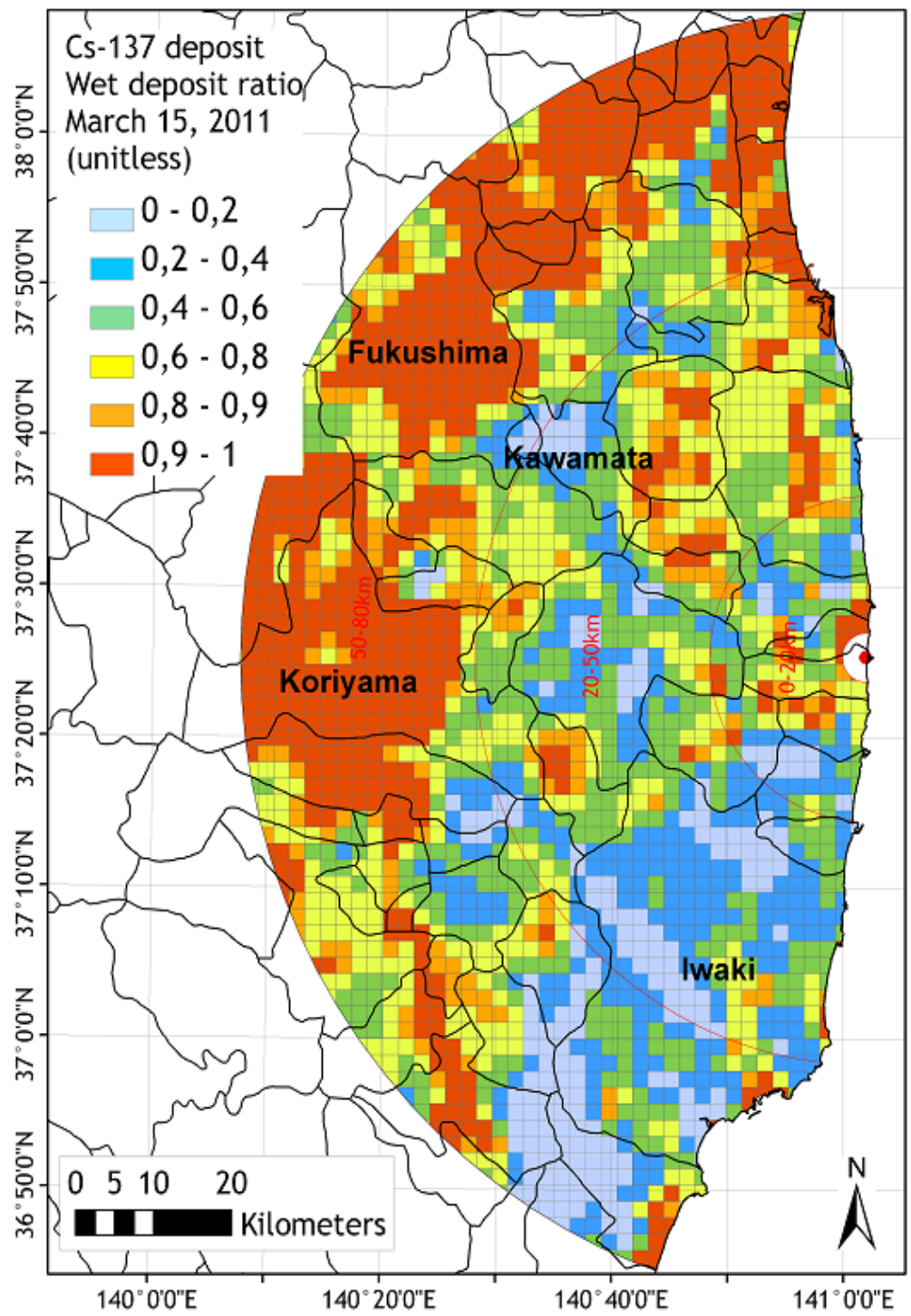

Wet fraction $>0.8$

Intense wet deposition might have occurred in the Abukuma valley \& to the NW of FDNPP

\section{Wet fraction $<0.4$}

Noticeable dry deposition might have occurred in S/SW regions = high forested areas of the Abukuma mountains 